\title{
Periodontally Assisted Osteogenic Orthodontic: Journey from Past to Present- a review
}

\author{
Dr.Falguni Mehta ${ }^{1}$, Dr.Vaibhav Gandhi ${ }^{2}$ \\ ${ }^{I}$ (Head of Department, Department of orthodontics, govt. Dental College and Hospital, Ahmedabad) \\ ${ }^{2}\left(3^{\text {rd }}\right.$ Year Post Graduate, Department of orthodontics, govt. Dental College and Hospital, Ahmedabad $)$
}

\begin{abstract}
Now a days increasing number of adult patient come for Orthodontic treatment who wants their braces off as early as possible. Adults are more concerned about their aesthetics even with braces. To overcome this kind of psychological or psychosocial problem, new Orthodontic techniques have emerged to reduce treatment duration without compromising stability. There have been theories suggested by various authors for rapid tooth movement. One of such theories is periodontically accelerated osteogenic Orthodontics (PAOO) which is patented by Wilckodontics, which is said to harness the regional acceleratory phenomenon (RAP). $P A O O$ technique definitely reduces treatment time than conventional orthodontic treatment. Studies also shows that, it increases alveolar bone thickness due to bone grafting, enhancing post orthodontic stability with lesser chances of root resorption.
\end{abstract}

Keywords: Adult Orthodontic, PAOO, Regional Acceleratory Phenomenon (RAP), Wilckodontics

\section{Introduction}

One of the major barriers with patient seeking orthodontic treatment is long duration of the treatment. Now a days increasing number of adult patient come for Orthodontic treatment who wants their braces off as early as possible [1].Growth is almost an insignificant factor in adults compared with children. In addition, there is an increased chance of hyalinization that can occur in adults when compared with adolescents [2]. All these factors make adult Orthodontic treatment a challenging therapeutic modality in dentistry, which necessitates the need for improvised concepts and procedures for the purpose of creating a functional dentition in a healthy periodontal environment. Moreover adults are more concerned about their aesthetics even with braces. To overcome this kind of psychological or psychosocial problem, new Orthodontic techniques have emerged to reduce treatment duration without compromising stability. The efficiency of Orthodontic tooth movement in these patients can be increased when well-planned force systems are applied to bony tissues that offer less resistance against the desired movement which results in faster Orthodontic movement, and treatment goals can be achieved in a shorter period, without compromising the results [3]. Orthodontic tooth movement can brought about by various techniques, with removable or fixed appliance, mini implants applying different types of force (continuous or intermittent) and different quantity of force (light or heavy). Not only would an ideal force allow for physiological tooth movement, it would also bring about quickest treatment time with least tissue damage.

However speed of tooth movement could be influenced by changing the environment in which teeth are housed (the periodontal ligament and bone). There have been theories suggested by various authors for rapid tooth movement. One of such theories is periodontically accelerated osteogenic Orthodontics (PAOO) which is patented by Wilckodontics [4] which is said to harness the regional acceleratory phenomenon (RAP) [5]. Corticotomy assisted Orthodontic treatment or PAOO may be considered as an intermediate therapy between Orthognathic surgery and conventional Orthodontics [6]. Interdisciplinancy Orthodontic tooth movement can synchronize with tissue engineering principles of periodontal regenerative surgery to create rapid Orthodontic movement and overcome its side effects [7].

\section{Literature Review}

Surgically assisted orthodontic tooth movement has been used since the 1800's. In 1893, Cunningham presented "Luxation, or the immediate method in the treatment of irregular teeth" at the International Dental Congress in Chicago. Corticotomy facilitated tooth movement was first described by LC Bryan in 1893 published in the textbook by SH Guiliford. It was Henrich Kole's publication in 1959; however that set the stage for evolution of corticotomy facilitated orthodontics [8]. Kole believed that it was the continuity and thickness of the denser layer of cortical bone that offered the most resistance to tooth movement. He theorized that by disrupting the continuity of this cortical layer of bone, he was actually creating and moving blocks of bone in which teeth were embedded. He postulated this theory as "bony block movement" [9].

Bell and Levy published the first experimental study of alveolar corticotomy in 49 monkeys in 1972. They described a model of vertical interdental corticotomy that should have been considered an osteotomy, because they mobilized all dento-osseus segments [10]. 
Duker et al conducted an experiment on beagle dogs in 1975 and demonstrated that rapid tooth movement could be achieved by orthodontic appliances after weakening the bone by corticotomy [11]. The rapid tooth movement does not affect the vitality of the teeth which have been moved. The health of the periodontium is also maintained by avoiding corticotomy of the marginal bone.

In 2001, however, Wilcko, et al. [4] challenged the concept of "bony block movement." They reported that in an evaluation of corticotomized patients, utilizing hospital-based high resolution CT scan imaging, that the small outlined blocks of bone lost their structural integrity due to an apparent demineralization of the alveolar housing over the root prominences. This apparent demineralization occurred in close approximation to the circumscribing corticotomy cuts both on the pressure side of the teeth and on the tension side of the teeth. The initial alveolar demineralization and subsequent remineralization was consistent with the cascading physiologic events associated with RAP and not "bony block movement."

Recently in 2008, Wilcko et al. [12] introduced a new technique known as Periodontally Accelerated Osteogenic Orthodontics (PAOO) which is the combination of selective decortication-facilitated Orthodontic technique and alveolar augmentation. This technique increases the net alveolar volume after orthodontic treatment by using bone grafts which consists of decalcified freeze dried bone allograft (DFDBA) which reduces the treatment time to $1 / 3^{\text {rd }}$ the time of conventional Orthodontic treatment.

Limitation of a conventional Orthodontic management is that in most cases the patient requires extraction, may result in relapse without the use of retainers, may compromise the health of periodontium due to excessive force and require a longer period of time for the completion of the treatment especially in adults.

\section{Regional Acceleratory Phenomenon (Rap)}

Orthopaedist Herald Frost in 1983 recognised that surgical wounding of osseous tissue results in striking reorganising activity adjacent to the site of injury (in osseous/ soft tissue surgery). He collectively termed this cascade of physiologic healing events -"The Regional acceleratory phenomenon" (RAP) [13, 14]. The RAP is a local response of tissues to noxious stimuli by which tissue regenerates faster than normal in a regional regeneration/remodeling process [15].This response varies directly in duration, size, and intensity with the magnitude of the stimulus. The duration of RAP depends on the type of tissue, and usually lasts about four months in human bone. This phenomenon causes bone healing to occur 10-50 times faster than normal bone turnover [16].

The healing phases of RAP have been studied in the rat tibia. There is an initial stage of woven bone formation, which begins in the periosteal area and then extends to medullary bone, reaching its maximal thickness on day seven. This cortical bridge of woven bone is a fundamental component of RAP, providing mechanical stability of bone after injury. From day seven, the woven bone in the cortical area begins to undergo remodeling to lamellar bone, but woven bone in the medullary area undergoes resorption, which means transitory local osteopenia. It seems that medullary bone needs to be reorganized and rebuilt after establishment of the new structure of cortical bone, and to adapt to the reestablishment of cortical integrity (three weeks in rats). There is also a systemic acceleratory phenomenon (SAP) of osteogenesis due to systemic release of humoral factors [16].

In human long bones, following surgical injury, RAP begins within a few days, usually peaks at 1-2 months, and may take from 6 to 24 months to subside completely [14]. RAP results in a decrease in regional bone densities (osteopenia) in healthy tissues whereas the volume of bone matrix remains constant. ${ }^{13}$ Orthodontic force application alone is a stimulant sufficient to trigger mild RAP activity. But when tooth movement is combined with selective decortication, RAP is maximized [16, 17]. However, in 2001 Wilcko et al revisited the original technique of bony block movement with some modifications.He attempted two cases with severely crowded dental arches, and speculated that the dynamics of physiologic tooth movement in patients who underwent selective decortication which might be due to a demineralization-remineralization process rather than bony block movement. They suggested that this process would manifest as a part of RAP that involves the alveolar bone after being exposed to injury (corticotomy) and during active tooth movement [6].

Wilcko, et al. [17] went on to report that the remineralization phase of the RAP was remarkably complete in the adolescent at two years post corticotomy surgery. In the adult however the remineralization was not only incomplete at two years post corticotomy surgery, but it was still incomplete at 12 years post corticotomy surgery with a net loss of alveolar bone. They attributed this net loss of alveolar bone in the adult to the decreased recuperative potential of adult bone in comparison to adolescent bone. Wilcko, et al. $[17,18]$ have additionally reported that the tooth movement can be best surgically facilitated by providing for a thin layer of activated bone over the root surfaces in the direction of the intended tooth movement. The demineralization of this thin layer of bone will leave the soft tissue matrix of the bone and islands of osteoid that can be carried with the root surfaces of the teeth where it will remineralize in the desired position. This remineralization process is almost complete in the adolescent, but only partially complete in the adult. 


\section{Indication}

$>$ For decrowding of the dental arches.

$>$ For reducing treatment time with sufficient stability.

$>$ For protraction of molars.

$>$ For early space closure in extraction case.

$>$ For single or segmental intrusion and treating open bite.

$>$ For expansion of arches in buccal region.

$>$ To facilitate eruption of impacted tooth.

\section{Contraindication}

$>$ Patients with systemic disease like diabetes mellitus, bleeding disorders, congenital heart disease, uncontrolled hypertension etc.

$>$ Patient with poor oral hygiene.

$>$ Patient with active periodontal disease

$>$ Patients on long term medications which will slow down bone metabolism, such as bisphosphanate and NSAIDs. NSAIDs lead to prostaglandin inhibition resulting in reduced osteoclastic activity thus disturbing bone remodeling.

$>$ Patients on long term steroid therapy due to the presence of devitalized areas of bone

$>$ Patients with compromised width of the attached gingiva.

\section{PAOO Technique}

Balance between resorption and deposition is very important factor for any kind of tooth movement. By modifying this balance we can bypass the waiting period for resorption and move the teeth farther without causing any irreversible damage to periodontium. This has been the topic of interest for many researchers $[8,9]$. In process of resorption the catabolic activity mediated by osteoclasts is the limiting factor in the rate of tooth movement in which periodontal ligament plays a crucial role [19].

This procedure is performed under local anaesthesia. Full thickness mucoperiosteal flap is reflected with proper releasing incisions.Flap should be reflected beyond root apices of teeth to be move if segmental molar intrusion required. The flaps should be extended beyond the corticotomy sites mesially and distally to prevent vertical releasing incisions. The interdental papilla can be reflected with the flap or left in place [12]. However the interdental papilla between the maxillary central incisors is preserved for aesthetic purposes [20].

Then vertical cortical scaring incisions are performed over interproximal cortical bone and extend beyond root apices. Then horizontal connecting incision is done. This is done both on buccal and palatal sides. Scaring can be done by piezoelectric knife or small round bur with sufficient irrigation. The purpose of scaring over bone is not to decorticate and separate the dentoalveolar segment. Only scaring is done in form of either vertical or horizontal incisions or dots over cortical plate to just alter or modify balance between resorption and deposition by means of production of RAP.

Bone graft material is placed over decorticated area. Most commonly used material for grafting is decalcified freeze dried bone allograft (DFDBA).Wilcko et al introduced the use of mix of demineralized freeze-dried bone with bovine bone and clindamycin. The particulate bone graft can also be wet with plate-rich plasma to facilitate the placement of the graft and to increase the stability of the graft material [21]. The volume of particulate bone graft used is $0.25-0.5 \mathrm{ml}$ per tooth. Excess amount of bone graft should be avoided to prevent tension over flap during closure.

Flap closure is done with non-resorbable silk suture material without building up tension over flap. The surgical sites should be vigorously irrigated with saline prior to flap repositioning and sutured. Suture should be kept in place for at least 2 weeks. No periodontal pack required. Analgesics and adjunctive antibiotics are prescribed for 1 week. Long-term administration of nonsteroidal anti-inflammatory agents is discouraged as these may interfere with the regional acceleratory process. Regular follow up is to be scheduled every 2 weeks during application of Orthodontic force after surgery.

\section{Conclusion}

PAOO technique definitely reduces treatment time than conventional orthodontic treatment. Studies also shows that, it increases alveolar bone thickness due to bone grafting, enhancing post orthodontic stability with lesser chances of root resorption. However, one should always keep in mind that proper case selection, diagnosis and treatment planning with good co-ordination is between orthodontist, periodontist and oral and maxillofacial surgeon would result in successful treatment by decreasing treatment time with minimum damage to the supporting tissue and teeth.

\section{References}


[1]. T.G. Rappaport, M.H. Shalis and E. Gazit. Psychosocial reward of orthodontic treatment in adult patients. European Journal of Orthodontics, 32(4), 2010, 441-446.

[2]. Ong MM, Wang HL. Periodontic and orthodontic treatment in adults. Am J OrthodDentofacialOrthop 2002;122:420-8.

[3]. Mathews DP, Kokich VG. Managing treatment for the orthodontic patient with periodontal problems. SeminOrthod 1997;3:21-38

[4]. Wilcko WM, Wilcko MT, Bouquot JE, et al: Rapid orthodontics with alveolar reshaping: Two case reports of decrowding. Int J Periodontics Restorative Dent 21:9, 2001

[5]. Frost HM : A 2003 update of bone physiology and Wolff's Law for clinicians: Angle Orthod. 2004 Feb;74(1):3-15

[6]. Gantes B, Rathbun E, Anholm M. Effects on the periodontium following corticotomyfacilitated orthodontics. Case reports.J Periodontol 1990;61:234-8

[7]. Little RM. Retention and stability in Orthodontics. Philadelphia: Saunders; 1993. Stability and relapse of dental arch alignment In Burstone CJ, Nanda R (eds) pp. 97-106.

[8]. Köle H. Surgical operations of the alveolar ridge to correct occlusal abnormalities. Oral Surg Oral Med Oral Pathol. 1959; 12: 51529

[9]. Kole H. Surgical operations on the alveolar ridge to correct occlusal abnormalities. Oral Surg Oral Med Oral Pathol. 1959; 12: 41320

[10]. Bell WH, Levy BM. Revascularization and bone healing after maxillary corticotomies. J Oral Surg. 1972; 30 : 640-8.

[11]. Duker J. Experimental animal research into segmental alveolar movement after corticotomy. J Maxillofac Surg. 1975 ; 3: 81-4.

[12]. M.T. Wilcko, W.M. Wilcko, and N.F. Bissada. An evidence-based analysis of periodontally accelerated orthodontic and osteogenic techniques: a synthesis of scientific perspectives. Seminars in Orthodontics , 14(4), 2008, 305-316.

[13]. Frost MH. The biology of fracture healing: An overview for clinicians Part I. Clin Ortho. 1989; 248: $283-93$.

[14]. Frost MH. The biology of fracture healing: An overview for clinicians Part II. Clin Ortho. 1989; 248: $294-309$.

[15]. Frost HM. The regional acceleratory phenomenon: a review. Henry Ford Hosp Med J. 1983; 31:3-9.

[16]. Schilling T, Müller M, Minne HW, Ziegler R. Influence of inflammation-mediated osteopenia on the regional acceleratory phenomenon and the systemic acceleratory phenomenon during healing of a bone defect in the rat. Calcif Tissue Int. 1998; 63: 1606.

[17]. Wilcko MT, Wilcko WM, Bissada NF. An evidence-based analysis of periodontally accelerated orthodonticand osteogenic techniques: A synthesis of scientific perspectives. SeminOrthod 14:305-316, 2008

[18]. Wilcko MT, Wilcko WM, Pulver JP, Bissada NF, Bouguot JE: Accelerated osteogenic orthodontics technique: a 1-stage surgically facilitated rapid orthodontic technique with alveolar augmentation. J OralMaxillofacSurg 67:2149-2159, 2009.

[19]. Suya H. Corticotomy in orthodontics. In Hosl E, Baldauf A (eds), Mechanical and Biological Basis in Orthodontic therapy. Germany: HuthigBuchVerlag; 1991: 207-26.

[20]. D.J. Ferguson, W.M. Wilcko and M.T. Wilcko. Selective alveolar decortication for rapid surgical-orthodontic resolution of skeletal malocclusion treatment. Distraction osteogenesis of the facial skeleton. (Italy, pmphusa, 2006) 199-203.

[21]. K.G. Murphy, M.T. Wilcko, W.M. Wilcko and D.J. Ferguson. Periodontally accelerated osteogenic orthodontics: a description of the surgical technique. J Oral MaxillofacSurg, 67(10), 2009, 2160-2166 